\title{
Artikel
}

\section{Armoede onder kinderen: een pleidooi voor een kindgerichte aanpak van armoedebestrijding}

\author{
Mr. E. Huls en mr. C. Vanderhilt*
}

\section{Inleiding}

Ondanks de economische vooruitgang de afgelopen jaren is het aantal kinderen in langdurige armoede nauwelijks gedaald. Volgens het meest recente rapport van het Centraal Bureau voor de Statistiek (CBS) groeien nog steeds 292.000 kinderen op in armoede. Van deze groep groeien 117.000 kinderen op in een gezin met een langdurig laag inkomen (ten minste vier jaar achter elkaar). ${ }^{1}$ Dit houdt in dat ongeveer één op de tien kinderen in armoede leeft. Het bestrijden van armoede en sociale uitsluiting onder kinderen in Nederland blijkt een grote uitdaging.

Dit beeld wordt bevestigd door gegevens in het onlangs verschenen Nederlands Nationaal Hervormingsprogramma 2019. ${ }^{2}$ Hierin wordt vermeld dat de kans op armoede en sociale uitsluiting voor de Nederlandse bevolking tussen 2008 en 2017, ondanks een tussentijdse lichte daling, zelfs is toegenomen van $14,9 \%$ tot $17 \%$. Dit percentage is de afgelopen jaren, dus ná de economische crisis, alleen maar gestegen.

* Mr. E. Huls is advocaat-in-dienstbetrekking bij Defence for Children Mr. C. Vanderhilt is projectmedewerker jeugdrecht bij Defence for Children. Dit artikel is in samenwerking met het Kinderrechtencollectief geschreven.

1. Centraal Bureau voor de Statistiek, Armoede en sociale uits/uiting 2018, Den Haag/Heerlen/Bonaire: 2018.

2. Zie: https://www.rijksoverheid.nl/documenten/rapporten/2019/02/27/ bijlage-1-rapport-nederlands-nationaal-hervormingsprogramma-2019.

Voor gezinnen die in armoede leven, is een quick-fix helaas niet mogelijk, terwijl uit onderzoek blijkt dat de gevolgen van armoede voor kinderen groot zijn. Aan de hand van drie actuele kwesties met betrekking tot armoede onder kinderen in Nederland geven wij een compacte beschrijving van het beeld dat wij hebben van het huidige beleid gericht op armoedebestrijding onder kinderen. Met die beschrijving hopen wij duidelijk en inzichtelijk te maken dat de anpak van armoede onder kinderen complex is. De drie kwesties hebben wij gekozen, omdat deze ook de basis vormen voor de vijfjaarlijkse rapportage aan het VN-Kinderrechtencomité over de naleving van kinderrechten in Nederland. In dit artikel zullen wij eerst kort stilstaan bij voornoemd rapportageproces alvorens de drie kwesties inhoudelijk te bespreken.

Daarnaast missen wij bij het vertrekpunt in het huidige beleid de stem van kinderen en jongeren. Defence for Children, Save the Children en Stimulansz hebben gezamenlijk het project Speaking Minds ${ }^{3}$ ontwikkeld. In dit artikel wordt dit project nader beschreven en toegelicht hoe de stem van kinderen en jongeren bij beleid kan worden betrokken.

Tot slot pleiten wij in dit artikel voor een andere benadering van bestrijding van armoede onder kinderen, waarbij de rechten van het kind als verbindende factor fungeren. In deze visie past tevens het opheffen van het voorbehoud bij artikel $26 \mathrm{VN}-$ Kinderrechtenverdrag (IVRK), teneinde mogelijk te maken dat kinderen en

3. Speaking Minds geeft jongeren een stem in het (gemeentelijk) armoede- en schuldenbeleid en is een programma van Save the Children, Defence for Children en Stimulansz. Zie: www.speakingminds.nl. 
jongeren zelfstandig recht krijgen op sociale voorzieningen in plaats van een afgeleid recht via hun ouder(s) of verzorger(s). Naar onze mening is deze stap noodzakelijk zodat kinderen en jongeren beter kunnen participeren in de huidige maatschappij.

'Eenzaamheid, je voelt je afgesloten voor anderen. Het lijkt alsof je geen kansen krijgt/hebt. Armoede betekent ook voor mij leegte. De gedachte van een normaal leven vult de geest, maar de leegte zmerft door je hele lichaam. Armoede betekent voor mij ook angst. Angst om te vragen en angst om te krijgen.'

Jongere die heeft deelgenomen aan Speaking Minds over de betekenis van armoede

\section{VN-Kinderrechtencomité}

Het gaat goed met Nederland. We vinden dat we een hoge kwaliteit van leven hebben en geven ons leven gemiddeld een $7,8 .{ }^{4}$ Het opleidingsniveau stijgt, de werkloosheid neemt af en onze koopkracht is hersteld. Toch gaat het ook niet goed met Nederland. Het aantal kinderen dat in langdurige armoede leeft, daalt niet of nauwelijks. Kinderen die veel risico lopen, zijn met name de kinderen behorende tot eenoudergezinnen, kinderen van bijstandsgerechtigden en kinderen met (ouders met) een niet-westerse afkomst. Het lukt Nederland niet om dit patroon te doorbreken. Dit is zorgelijk. Hoewel kinderen het recht hebben op een toereikende levensstandaard (art. 27 IVRK), is dit recht voor veel kinderen illusoir geworden.

Het VN-Kinderrechtencomité heeft reeds in 2015 diverse aanbevelingen (concluding observations) ${ }^{5}$ aan Nederland gedaan, gericht op de bestrijding van armoede onder kinderen. In aanloop naar de vijfde periodieke rapportage van de Nederlandse regering an het VNKinderrechtencomité over de naleving van kinderrechten in Nederland, hebben non-gouvernementele organisaties op 1 juli 2019 hun input voor de Written Inputs to the List of Issues Prior to Reporting (LOIPR) ingediend. Het is daarbij voor het eerst dat de rapportageverplichting verloopt via een simplified reporting procedure. ${ }^{6}$ Ten behoeve van het opstellen van een lijst met issues heeft het Kinderrechtencollectief ${ }^{7}$ met verschillende partijen gesproken. Uitgangspunt daarbij vormden de aanbevelingen die het $\mathrm{VN}-$ Kinderrechtencomité tijdens de rapportageprocedure in 2015 heeft geformuleerd. Een belangrijk onderwerp op de list of issues van non-gouver-

4. Sociaal en Cultureel Planbureau, De sociale staat van Nederland 2018 , Den Haag: september 2018.

5. $\mathrm{CRC} / \mathrm{C} / \mathrm{NDL} / \mathrm{CO} / 4$, p. 2.

6. Het verschil met de standaard rapportageprocedure is dat staten nu niet meer verplicht zijn om zowel een regeringsrapportage als schriftelijke antwoorden op de list of issues aan te leveren, maar hiervan één stap wordt gemaakt.

7. Het Kinderrechtencollectief is in 1995 opgericht en bestaat uit verschillende kinderrechtenorganisaties. Dit zijn Defence for Children, de Nederlandse Jeugd Raad, Stichting Kinderpostzegels Nederland, UNICEF Nederland, Terre des Hommes en Save the Children. nementele organisaties is armoede onder kinderen. Drie prangende kwesties komen tijdens en na de consultatiefase met diverse professionele partijen hoofdzakelijk aan de orde. Welke drie kwesties zijn dit en waardoor worden deze in stand gehouden?

\section{Gebrek aan landelijke visie c.q. sturing in het garanderen van het recht van alle kinderen op bestaanszekerheid (als fundament voor ontwikkeling en meedoen)}

Gemeenten zijn vrij in het voeren van armoedebeleid. Echter, landelijke regiedoelstellingen ontbreken, zodat niet kan worden vastgesteld hoe effectief het armoedebeleid is. Er wordt nog onvoldoende ingezet op integraal kindgericht armoedebeleid dat het leven van kinderen op alle vlakken verbetert. ${ }^{8}$ Daarnaast wordt door gebrek aan communicatie over dit onderwerp het taboe dat rust op armoede- en schuldenproblematiek in stand gehouden.

Schokkend was het bericht van de Sociaal-Economische Raad (SER) dat $60 \%$ van de kinderen die in armoede leeft, werkende ouders heeft. ${ }^{9}$ Werken loont dus niet altijd. ${ }^{10}$ Door het (hogere) loon vervalt het recht op kwijtscheldingen bij schulden snel en worden tegemoetkomingen in een rap tempo verminderd. Daarnaast geldt dat Nederland een stelsel van toeslagen voor kinderen heeft, waarvan een deel inkomensafhankelijk is (bijvoorbeeld het kindgebonden budget). De aanvraag van voorzieningen, zoals kinderopvangtoeslag, is ingewikkeld en ontoegankelijk. Daarnaast lopen gezinnen risico's van terugbetaling, ${ }^{11}$ zelfs bij een minieme inkomensstijging. Terugbetaling is veelal onmogelijk, waardoor schulden ontstaan. Ontoegankelijkheid en risico's veroorzaken ook dat gezinnen geen gebruik van de regelingen durven maken. ${ }^{12}$

Bovendien is er een gebrek aan deskundigheid omtrent de aanpak van armoede- en schuldenproblematiek in de gemeentelijk georganiseerde (hulpverlenings)keten, terwijl $80 \%$ van alle vragen bij de sociale (wijk)teams en integrale intakes over financiën gaan. ${ }^{13}$

8. Centraal Bureau voor de Statistiek, Armoede en sociale uits/uiting 2018, Den Haag/Heerlen/Bonaire: 2018.

9. Sociaal-Economische Raad, Opgroeien zonder armoede, Den Haag: 2017.

10. Sociaal Cultureel Planbureau, Als werk weinig opbrengt: Werkende armen in vijf Europese landen en twintig Nederlandse gemeenten, Den Haag: 2018.

11. Kamerstukken I/ 2018/19, 35000 XV nr. 00, Vaststelling van de begrotingsstaten van het Ministerie van Sociale Zaken en Werkgelegenheid (XV) voor het jaar 2019, antwoord op vraag 340: 'Voor 2016 is 96,7\% van de voorgeschoten kinderopvangtoeslag definitief vastgesteld. Bijna 240.000 huishoudens van de bijna 530.000 waar de kinderopvangtoeslag definitief is toegekend (45\%) kregen te maken met een terugvordering van gemiddeld $€$ 615.'

12. Nibud, 18 april 2019, persbericht 18 april 2019: 'Kwart van huishoudens weet niet of ze recht hebben op toeslagen', https://www.nibud.nl/ consumenten/nibud-kwart-van-huishoudens-weet-niet-of-ze-rechthebben-op-toeslagen/.

13. VNG e.a., Naar een betere aanpak van schulden en armoede, 2016. 
'Armoede is een netwerk van sociale uitsluitingen. Het strekt zich uit over meerdere gebieden van het individuele en collectieve bestaan, dermate dat de armen morden gescheiden van de algemeen aanvaarde leefpatronen van de samenleving. Deze kloof kunnen ze niet op eigen kracht overbruggen.'

Jongere die heeft deelgenomen aan Speaking Minds over de betekenis van armoede

\section{- Geen reductiedoelstelling}

Een groot gemis is met name een landelijk geformuleerde reductiedoelstelling. ${ }^{14}$ In de Kamerbrief van 6 april 2018 (Kabinetsreactie op het SER-advies en op het rapport van de Kinderombudsman) wordt genoemd dat de gezamenlijke partijen - CBS, Centraal Planbureau (CPB) en Sociaal en Cultureel Planbureau (SCP) opdracht hebben gekregen om te onderzoeken of het mogelijk is tot uniforme armoede-indicatoren te komen die bruikbaar zijn voor een eventuele reductiedoelstelling. ${ }^{15}$ Immers, ondanks dat zowel het CBS als het SCP armoede definiëren als het hebben van onvoldoende financiële middelen om een bepaald consumptieniveau te realiseren dat in Nederland als minimaal noodzakelijk wordt geacht, hanteren zij verschillende indicatoren voor het meten van armoede. De verschillen zitten met name in de vaststelling van de armoedegrens en het gehanteerde inkomensbegrip. Bovendien zijn beide indicatoren gericht op inkomensarmoede, die zij vanuit een ander perspectief belichten. Het inkomensbegrip wordt vastgesteld aan de hand van het besteedbaar inkomen, waarbij het CBS geen inkomenstoeslagen meeneemt zoals de huurtoeslag en kosten van kinderopvang na aftrek van de kinderopvangtoeslag. ${ }^{16}$

Het SCP daarentegen stelt de armoedegrens vast aan de hand van het niet-veel-maar-toereikend-budget. ${ }^{17} \mathrm{Om}$ het besteedbaar inkomen vast te stellen, wordt rekening gehouden met het inkomen uit arbeid, uitkeringen en pensioenen, verminderd met betaalde belastingen en premies. Op die manier worden de huurtoeslag en de kosten van kinderopvang (na aftrek van de kinderopvangtoeslag) wel meegerekend. ${ }^{18}$

In Europees verband wordt de armoedegrens uitgedrukt als een percentage van het mediane inkomen. ${ }^{19}$ De grens wordt vastgesteld per land, het percentage is meestal 60 . De uitdrukking van armoede onder kinderen omvat

14. Een doelstelling om het aantal kinderen dat in armoede leeft jaarlijks met een bepaald percentage structureel te verminderen.

15. T. van Ark, (2018). Kabinetsreactie op SER-advies 'Opgroeien zonder armoede' en reactie op rapport Kinderombudsman 'Alle kinderen Kansrijk'.

16. Sociaal-Economische Raad, Opgroeien zonder armoede, Den Haag: 2017, p. 24.

17. De armoedegrens is gebaseerd op een lijst met minimaal noodzakelijke goederen en voorzieningen met daaraan gekoppelde referentiebedragen.

18. $\mathrm{CPB} / \mathrm{SCP} / \mathrm{CBS}$, Verkenning naar eenduidige indicatoren kinderarmoede, oktober 2018, p. 6.

19. Het mediane inkomen is het inkomen waarbij de helft van het aantal huishoudens een hoger inkomen en de andere een lager inkomen heeft. naast het risico op armoede ook zelfgerapporteerde materiële armoede en lage werkintensiteit. ${ }^{20}$

Inmiddels hebben het CBS, het CPB en het SCP schriftelijk laten weten dat het mogelijk is om inzicht te geven in de verschillende facetten van kinderen in armoede. ${ }^{21}$ Dit kan door bovenop de bestaande indicatoren ten behoeve van het belichten van inkomensarmoede, indicatoren te ontwikkelen die ook de mate van sociale uitsluiting en 'kansarmoede' in kaart brengen. Op deze manier wordt zicht verkregen op de andere facetten van armoede (zoals het hebben van vermogen, de toegankelijkheid van onderwijs en zorg, schoolprestaties, gezondheid en leefomgeving). Tevens geven het CBS, het CPB en het SCP aan dat de ondersteuning van gemeentelijk armoedebeleid, gericht op kinderen, in kaart kan worden gebracht door het bouwen van een register voor gemeentelijke maatregelen. Duidelijk wordt wel dat een investering moet worden gedaan door de Rijksoverheid teneinde dit te kunnen bewerkstelligen.

Sinds diverse aangenomen moties in zowel de Eerste als Tweede Kamer waarin de regering wordt verzocht met een voorstel te komen tot een reductiedoelstelling om armoede onder kinderen daadwerkelijk te verlagen, is ruim een jaar vestreken. ${ }^{22} \mathrm{Er}$ is nog steeds geen reductiedoelstelling geformuleerd. Gelet op de laatste Kamerbrief van staatssecretaris Van Ark aan de Tweede Kamer gaat die reductiedoelstelling er ook niet komen. Volgens Van Ark is een kwantitatieve reductiedoelstelling voor het verminderen van armoede onder kinderen niet te definiëren, aangezien armoede niet in één getal te vangen is. Als redenen worden onder meer genoemd dat er verschillende definities van armoede of een risico op armoede zijn en het effect van het gemeentelijke armoedebeleid en de kansarmoede niet in de armoedecijfers zijn opgenomen. ${ }^{23}$ Dit staat echter lijnrecht tegenover de bevindingen van het CBS, het CBP en het SCP. Volgens deze bureaus is het namelijk wél mogelijk om een landelijk beeld te verkrijgen van het aspect kinderarmoede door de bestaande indicatoren voor het meten van armoede uit te breiden met meerdere facetten, zoals gezondheid, leefomgeving en het hebben van voldoende vermogen..$^{24}$ Uitstel van die reductiedoelstelling is dan ook onbegrijpelijk en kan niet langer als verantwoord worden beschouwd. Om armoede onder kinderen daadwerkelijk terug te dringen alsook de effectiviteit van inspanningen te kunnen meten, is een reductiedoelstelling van fundamenteel belang.

20. Sociaal-Economische Raad, Opgroeien zonder armoede, Den Haag 2017, p. 26.

21. $\mathrm{CPB} / \mathrm{SCP} / \mathrm{CBS}$, Verkenning naar eenduidige indicatoren kinderarmoede, oktober 2018, p. 9-10.

22. Kamerstukken I/ 2016/17, 24515 nr. 391; Kamerstukken II 2016/17, 24515 nr. 405; Kamerstukken I 2017/18, 34775 D.

23. T. van Ark, (2019). Ambities Kinderarmoede.

24. $\mathrm{CPB} / \mathrm{SCP} / \mathrm{CBS}$, Verkenning naar eenduidige indicatoren kinderarmoede, oktober 2018, p. 4. 
2 Gebrek aan een effectieve aanpak van structurele - armoede onder kinderen in

Nederland, veroorzaakt schending van het recht op gelijke toegang tot (effectief) armoedebeleid

voor kinderen in alle gemeenten

Gemeenten bieden veel hulp in 'natura' gericht op het verbeteren van het leven van kinderen buitenshuis. Hierbij valt te denken aan een fiets, winterjas of gratis zwemkaart. Alhoewel sociale participatie essentieel is voor een goede ontwikkeling van kinderen en jongeren, wordt door deze maatregelen in natura de instabiele en onzekere thuissituatie van kinderen nog onvoldoende aangepakt. $^{25}$ Zo blijven de oorzaken van armoede bestaan, al worden de gevolgen van armoede enigszins verzacht.

Sinds 2017 stelt het kabinet structureel $€ 100$ miljoen beschikbaar (de zogenaamde 'Klijnsmagelden') voor armoedebestrijding, specifiek gericht op armoede onder kinderen. Hiervan gaat $€ 85$ miljoen naar gemeenten via een decentralisatie-uitkering. Destijds is besloten om dit geld niet te oormerken. Helaas bleek vervolgens uit verschillende bronnen dat het geld niet altijd terecht lijkt te komen bij kinderen die in armoede leven; bijvoorbeeld uit de uitzending van Nieuwsuur d.d. 24 november $2017,{ }^{26}$ evenals uit gesprekken die Save the Children en Defence for Children hebben gevoerd met beleidsmakers van verschillende gemeenten in het kader van ons programma Speaking Minds. ${ }^{27}$ De eerste evaluatie van de 'Klijnsmagelden' verricht door Bureau Bartels ${ }^{28}$ laat onder meer zien dat weinig gemeenten feitelijke verantwoording (hebben) kunnen afleggen over de besteding van de gelden en dat in elk geval 27\% niet aan armoedebeleid gericht op kinderen is besteed. Dit komt neer op ruim $€ 14$ miljoen. Tevens is bijna $€ 4$ miljoen terechtgekomen in de pot algemene middelen. ${ }^{29}$

Voorts blijkt dat slechts $17 \%$ van de totaal 303 aan deze evaluatie deelnemende gemeenten de impact van hun beleid in beeld heeft laten brengen. Dit lage percentage in onderlinge samenhang bezien met het vorige punt (geen feitelijke cijfermatige onderbouwing van de besteding van de gelden) roept vragen op. Elk zicht op een significant deel van de besteding van de Klijnsmagelden ontbreekt en zal niet inzichtelijk worden indien gemeenten niet op korte termijn dit in beeld (willen) brengen.

25. Centraal Bureau voor de Statistiek, Armoede en sociale uits/uiting 2018, Den Haag/Heerlen/Bonaire: 2018.

26. Zie: https://nos.nl/nieuwsuur/artikel/2204384-geld-voor-arme-kinde ren-verdwijnt-in-schuldenberg-gemeenten.html.

27. Speaking Minds geeft jongeren een stem in het (gemeentelijk) armoede- en schuldenbeleid en is een programma van Save the Children, Defence for Children en Stimulansz. Zie: www.speakingminds.nl.

28. Bureau Bartels, Eerste evaluatie van de bestuurlijke afspraken tussen SZW en VNG over kinderen in armoede, Amersfoort: 2018. De evaluatie betreft het jaar 2017.

29. Deze bedragen zijn op basis van de $€ 51$ miljoen waarover financiële verantwoording afgelegd kon worden. Wanneer gekeken wordt naar het totale bedrag van $€ 85$ miljoen, zou het bedrag dat niet goed besteed is wellicht nog (veel) hoger kunnen liggen, temeer omdat er gemeenten zijn (20\%) die niet aan het onderzoek mee wilden doen/ hebben gedaan.
Opvallend is dat bij dit soort onderzoeken telkens wordt aangesloten bij de door de gemeente gehanteerde definitie van de doelgroep en niet door een landelijk bepaalde definitie. Vaststaat dat ten aanzien van kindvoorzieningen geen landelijke normen zijn vastgesteld, waardoor verschillen tussen gemeenten zichtbaar zijn. Gemeenten hanteren bijvoorbeeld verschillende inkomenseisen om in aanmerking te komen voor een voorziening. De ene gemeente houdt $120 \%$ van het minimumloon aan, de andere gemeente $130 \%$. De postcode van het kind bepaalt dus pelke voorzieningen het kan krijgen. Dit vinden wij onverteerbaar.

\section{Opheffen voorbehoud artikel 26 IVRK}

Daarnaast heeft Nederland als enige land ter wereld een voorbehoud gemaakt bij artikel 26 IVRK. Dit houdt in dat kinderen in Nederland geen zelfstandig recht hebben op sociale zekerheid en dus niet zelfstandig aanspraak kunnen maken op sociale voorzieningen. Ondanks belangrijke rapporten van de Kinderombuds$\operatorname{man}^{30}$ is er geen voortgang met betrekking tot de intrekking van dit voorbehoud. In maart 2019 heeft de VNMensenrechtenraad een resolutie aangenomen die oproept tot volledige implementatie van het UNCRC door alle partijen. ${ }^{31}$

In Nederland zijn de implicaties van (het opheffen van) het voorbehoud nooit onderzocht. Een eerste stap zou dan ook zijn om minimaal te onderzoeken wat de mogelijke gevolgen en bezwaren zijn van het opheffen van het voorbehoud, maar ook of het opheffen hiervan in positieve zin kan bijdragen aan het creëren van een effectieve aanpak om armoede onder kinderen te bestrijden.

'Investeer in middelen die onze kinderen nodig hebben om een zo goed mogelijke basis te leggen voor een gezonde toekomst.'

Jongere die heeft deelgenomen aan Speaking Minds over wat anders zou moeten om Nederland een beter land te maken om in te wonen

\section{Wat zijn de gevolgen van armoede voor kinderen?}

Dat één op de tien kinderen in armoede leeft, betekent dat er in iedere schoolklas kinderen zitten bij wie thuis niet genoeg geld is om bijvoorbeeld eten of kleding te kopen of de verwarming aan te zetten. Voor deze kinderen is het niet vanzelfsprekend om lid te worden van een sportvereniging, te trakteren voor hun verjaardag of uitstapjes te maken. Zij kunnen niet mee als hun leeftijdsgenoten naar de bioscoop of met elkaar uit eten gaan.

30. Kinderombudsman, Alle kinderen kansrijk. Het verbeteren van de ontwikkelingskansen van kinderen in armoede, Den Haag: 2017, en Kinderombudsman, Nederlandse kinderen ontkoppeld, Den Haag: 2017.

31. https://www.eurochild.org/news/news-details/article/three-resolutions -with-an-impact-on-childrens-rights-adopted-by-human-rightscouncil/?no_cache $=1$ in het kader van het 30 -jarig bestaan van het IVRK. 
Daar komt bij dat kinderen er niet altijd even makkelijk over praten als zij omwille van een gebrek aan financiële middelen niet mee kunnen. Sommige kinderen schamen zich zelfs voor hun thuissituatie. Sociale uitsluiting ligt op de loer en dat is allesbehalve gunstig voor de ontwikkeling en het welzijn van kinderen. ${ }^{32}$

Een positieve ontwikkeling van het kind wordt ook bepaald door de veilige gehechtheid van een kind en de relatie tussen ouder en kind. Uit onderzoek blijkt dat weinig kinderen in arme gezinnen veilig gehecht zijn, waardoor zij bijvoorbeeld vaker gedragsproblemen hebben. ${ }^{33}$ Daarnaast hebben kinderen die opgroeien in een gezin met een laag inkomen een groter risico op een mindere hersenontwikkeling en heeft het invloed op hun schoolloopbaan. Recent onderzoek laat zien dat ouders met kinderen in achterstandswijken vaker te maken hebben met een complexe thuissituatie. ${ }^{34}$ Dit is van invloed op hun gedrag, ontwikkeling en toekomstperspectief. Kinderen met dezelfde capaciteiten, maar afkomstig van ouders die een lager inkomen hebben, krijgen vaker een lager advies dan kinderen van welgestelde ouders. Ook het opleidingsniveau van de ouders is hierin bepalend. Kinderen van lager opgeleide ouders hebben regelmatig een achterstand in hun ontwikkeling op het moment dat zij naar school gaan. ${ }^{35}$

Daarnaast komt in gezinnen met laagopgeleide ouders en gezinnen die te maken hebben met armoede vaker kindermishandeling voor en is armoede een factor die bijdraagt aan delinquent gedrag onder jongeren. Hoe langer een gezin in armoede leeft, hoe groter de kans is dat de kinderen fysieke en psychische problemen krijgen. Hun leven biedt weinig stabiliteit en hun toekomstperspectief is onzeker. ${ }^{36}$ Statistisch onderzoek toont dan ook aan dat kinderen en jongeren in armoede negatiever zijn over hun leven dan kinderen die daar niet mee te maken hebben. ${ }^{37}$ Bovendien hangt armoede vaak samen met het hebben van schulden. Kinderen die in armoede opgroeien, komen sneller in een sociaal isolement terecht en lopen een groter risico op dakloosheid. Aangezien ook de ouders onder grote (financiële) druk staan, komt met name langdurige armoede de band tussen ouders en kind niet ten goede. Ondanks dat de meeste kinderen die opgroeien in armoede niet meer arm of sociaal uitgesloten zijn op het moment dat zij volwassen zijn, is het risico daarop voor hen groter, met name wanneer zij als kind langdurig arm waren. Dit betreft de zogenoemde overerfbare armoede. ${ }^{38}$

32. Nederlands Jeugdinstituut, Opgroeien en opvoeden in armoede, Utrecht: maart 2018, p. 5

33. Nederlands Jeugdinstituut, Opgroeien en opvoeden in armoede, Utrecht: maart 2018, p. 18.

34. ABN AMRO Foundation en MWM2, Problematiek op basisscholen in achterstandswijken is fors, 2019.

35. Sociaal-Economische Raad, Opgroeien zonder armoede, Den Haag: 2017, p. 33.

36. Nederlands Jeugdinstituut, Opgroeien en opvoeden in armoede, Utrecht: maart 2018, p. 20.

37. Kinderombudsman, Alle kinderen kansrijk. Het verbeteren van de ontwikkelingskansen van kinderen in armoede, Den Haag: 2017, p. 33.

38. Nederlands Jeugdinstituut, Opgroeien en opvoeden in armoede, Utrecht: maart 2018, p. 22.

\section{Jongerenparticipatie}

Het is inmiddels duidelijk dat de armoedeproblematiek onder kinderen en jongeren blijft voortduren. Participatie van kinderen en jongeren is onmisbaar bij het vinden van oplossingen voor de anpak van armoedeproblematiek.

Om bij te kunnen dragen aan het versterken van de positie van kinderen en jongeren die opgroeien in armoede in de maatschappij en jongeren een stem te geven in het gemeentelijk armoedebeleid, is het programma Speaking Minds ontwikkeld. Speaking Minds brengt een dialoog tot stand tussen jongeren (waaronder jongeren die opgroeien in een huishouden met een laag inkomen) en beleidsmakers. De grondslag hiervoor is het recht op een toereikende levensstandaard (art. 27 IVRK) en het recht op participatie (art. 12 IVRK).

Binnen Speaking Minds worden jongeren via het voortgezet onderwijs, mbo en het praktijkonderwijs gekoppeld aan beleidsmakers. De beleidsmakers formuleren een beleidsvraag die te maken heeft met het terugdringen van armoede en schulden en het voorkomen van sociale uitsluiting. De jongeren buigen zich vervolgens over het vraagstuk en brengen hun advies daarover uit. De beleidsmakers krijgen ook een training over kinderrechten en betekenisvolle jongerenparticipatie. $\mathrm{Na}$ een aantal maanden wordt door de beleidsmakers een terugkoppeling gegeven aan de jongeren wat er met hun adviezen is gedaan of wordt gedaan. Dit leidt tot een inclusief en effectief armoedebeleid, dat aansluit bij de wensen en behoeften van jongeren en bijdraagt aan het tegengaan van sociale uitsluiting.

Tijdens de Speaking Minds trajecten komt het begrip armoede aan bod. Wat verstaan jongeren onder armoede en wanneer vinden zij dat zij een toereikende levensstandaard hebben? De betekenis van armoede verschilt onder hen. Algeheel kan worden gesteld dat zij niet alleen een gebrek an financiële middelen ervaren als armoede, maar dat ook andere factoren hieraan bijdragen. Als voorbeeld wordt genoemd dat zij vaak alleen zijn doordat zij niet kunnen sporten of uitstapjes kunnen maken en daardoor in een sociaal isolement verkeren. Zij interpreteren het armoedebegrip breder dan inkomensarmoede.

'Armoede betekent voor mij niet alleen te weinig eten, drinken en geen onderdak hebben maar ook het gemis van het gevoel dat je mag bestaan en dat er een plek voor jou is in de maatschappij. Ik denk dat deze mensen niet alleen meer aandacht zouden moeten krijgen maar ook een luisterend oor en een stukje saamhorigheid.'

Jongere die heeft deelgenomen aan Speaking Minds over de betekenis van armoede 


\section{Conclusie en aanbevelingen}

Bij de bestrijding van armoede en sociale uitsluiting staat volgens de Nederlandse overheid het vergroten van arbeidsparticipatie voorop. Het hebben van werk garandeert echter niet altijd een weg uit armoede. ${ }^{39}$ Het SCP concludeert dat gemeenten in hun beleid weinig specifieke aandacht besteden aan werkende armen en niet goed weten hoe ze deze groep moeten bereiken. Tevens hebben zes op de tien $(60 \%)$ kinderen die in armoede opgroeien, ouders die werken.

Ook de $\mathrm{SER}^{40}$ concludeert dat het aantal kinderen in armoede in Nederland nog altijd hoog is en nauwelijks daalt. Gesteld wordt dat het gebruik van bestaande voorzieningen, zoals kindregelingen, kindpakketten en toeslagen, veel beter moet, zowel voor de kinderen in armoede met ouders die een uitkering ontvangen, als voor de kinderen met werkende ouders. Het doel van deze voorzieningen moet zijn dat het kinderen perspectief biedt om uit een armoedesituatie te komen. Doordat de inzet van de Klijnsmagelden wordt beperkt tot hulp in natura, worden niet de structurele oorzaken van armoede angepakt. Momenteel blijft het dus bij 'pleisters plakken'.

Wij delen die conclusies en menen dat de inkomenspositie van ouder(s)/verzorger(s) als vertrekpunt voor het maken van beleid niet langer de geëigende weg is om armoede onder kinderen effectief te kunnen bestrijden. Vanzelfsprekend is het inkomen van de ouder(s)/ verzorger(s) relevant, maar daarnaast spelen ook andere facetten een rol, zoals sociale uitsluiting en kansarmoede. Om te kunnen bepalen wat nodig is om de armoedeproblematiek aan te pakken, is het de hoogste tijd dat de behoeften van het kind centraal worden gesteld. Wat heeft een kind anno 2019 en in de (nabije) toekomst nodig? Kunnen de ouder(s)/verzorger(s) hierin voldoende voorzien? Of is een anvullende voorziening noodzakelijk? Bij een benadering vanuit de behoefte van het kind, heeft het kind het recht op die aanvullende voorziening. Het kind is in dezen het rechtssubject. Alleen op die wijze kan een toereikende levensstandaard worden bepaald. Wij pleiten voor het stoppen met het maken van beleid waarbij het kind als een afgeleide wordt beschouwd van de ouder(s)/verzorger(s) en waarbij niet het kind, maar het gezinsinkomen centraal staat. Daarvoor moet het voorbehoud bij artikel 26 IVRK worden opgeheven. De Rijksoverheid maar ook de lagere overheid dient de situatie door de ogen van het kind te bekijken. Kinderen moeten worden betrokken bij het opstellen en uitvoeren van beleid, zodat hun behoeften het uitgangspunt vormen. En dat omvat, zoals uit de definitiebepaling van enkele jongeren die hebben deel- genomen aan Speaking Minds volgt, zo veel meer dan alleen het (gezins)inkomen.

'Meer kijken naar de behoeftes van de inmoners dan naar het financiële plaatje.'

Jongere die heeft deelgenomen aan Speaking Minds over wat anders zou moeten om Nederland een beter land te maken om in te wonen

Aanbevelingen wet- en regelgeving:

1. Hef het voorbehoud bij artikel 26 IVRK op.

2. Wijzig en vereenvoudig het belastingstelsel.

Aanbevelingen voor beleidsmakers en de praktijk:

3. Formuleer een kindgericht, landelijk en uniform uitgangspunt bij de bestrijding van armoede onder kinderen, waarbij de behoeften van een kind centraal staan en de toereikende levensstandaard bepalen.

4. Betrek kinderen en jongeren bij het beleid, gericht op armoedebestrijding.

5. Formuleer een reductiedoelstelling conform de bevindingen van het CBS, het SCP en het CPB.
39. Sociaal Cultureel Planbureau, Als werk weinig opbrengt: Werkende armen in viff Europese landen en twintig Nederlandse gemeenten, Den Haag: 2018. Hieruit blijkt dat het aandeel werkende armen sinds 1990 is gestegen.

40. Sociaal-Economische Raad, Opgroeien zonder armoede, Den Haag: 2017. 